Revista Iberoamericana, Vol. LXXV, Núm. 227, Abril-Junio 2009, 459-474

\title{
MONSTRUOSA COMPENSACIÓN. PERIPECIAS DE UN ESCRITOR CONTEMPORÁNEO EN WASABI DE ALAN PAULS
}

\author{
POR \\ Alejandra Laera \\ Universidad de Buenos Aires / CONICET
}

En Monstrous Imagination (1993), Marie-Hélène Huet explica la historia de la monstruosidad en relación con el acto de la procreación y propone un recorrido que va de la reproducción biológica a la creación literaria. Si en los siglos xvi y xvII está el llamado "monstruo de Ravena” con sus falsos parecidos y después la figura romántica del artista como creador, al final del camino Huet presenta el cuento de Jorge Luis Borges "Pierre Menard, autor del Quijote" como impugnación de las nociones de autoría y creación que serían propias del arte. El punto de llegada parece obvio tratándose del cuento de Borges, pero lo importante es que Huet destaca que es precisamente la semejanza entre el fragmento escrito por Cervantes y la escritura del Quijote emprendida por Menard lo que devela una aberración; lo monstruoso radicaría en lo diferente en el parecido y no en una deformación de la versión menardiana respecto del original cervantino. De las observaciones de Huet podría inferirse que, en la escritura moderna, es la propia autoría la que conlleva la monstruosidad. ${ }^{1}$

En ese cruce entre monstruosidad y procreación, entre deformidad y autoría, la lectura de Wasabi (1994) de Alan Pauls ofrece algo más que el abordaje del aspecto monstruoso que toda historia de vida sublima y que la novela pone a la luz, y también algo más que el acercamiento a los fantasmas propios de la subjetividad de un escritor, que la novela encarna ficcionalizando datos biográficos del propio autor. Leída en ese cruce, la historia del escritor que debe pasar tres meses en la localidad francesa de Saint-Nazaire a causa de un premio por el cual está comprometido a escribir un libro, y al que le empieza a crecer un quiste cada vez mayor en la nuca, supera el

\footnotetext{
1 En la literatura latinoamericana podría llevarse a cabo un recorrido similar al que, culminando en Borges, propone Huet: desde la monstruosidad de lo parecido pero diferente presente en las representaciones de las crónicas de Indias, hasta los nuevos monstruos de las novelas de Roberto Bolaño (La literatura nazi en América, Estrella distante) que involucran la idea de creación y, en particular, de creación literaria. En todos los casos, el mundo cotidiano es conmovido por la irrupción de cuerpos que son explicados mediante la apelación a la monstruosidad, ya sea una deformación o una duplicidad aberrante. Se trata, siempre, de las amenazas y ansiedades provocadas por los nuevos cuerpos pero, también, de los nuevos horrores de la sociedad moderna y su correlato deshumanizador.
} 
trauma individual. En cambio, adquiere una nueva dimensión y resulta el síntoma de un dilema que atraviesa la propia novela Wasabi, y que además recorre, de un modo u otro, buena parte de la narrativa contemporánea y de las preocupaciones críticas. ¿De qué modo conciliar las demandas externas, de corte simbólico o contractual, con los compromisos internos, sean del orden de la imaginación o de la estética? ¿Cuál es la porción de control sobre el acto de creación y la obra que es posible resignar sin renunciar al derecho total sobre ambos? ¿Cómo compensar esa pérdida? ¿Dónde se expresan esos dilemas: en la escritura, en el propio cuerpo del autor o en el tipo de circulación del escritor y del libro? Y finalmente, ¿de qué hablan esos dilemas: de problemas individuales, de modelos de escritor, de poéticas, de disputas estéticas, de un cambio de paradigma artístico? En el marco de una teoría de lo monstruoso que culmina en la actividad literaria, el quiste que deforma el cuerpo del escritor protagonista de Wasabi permite formular algunas respuestas desde el mismo campo de la narrativa ficcional.

WASABI Y SUS EXCESOS

Publicada en 1994 por la sede argentina de la editorial Alfaguara, Wasabi, del narrador y ensayista argentino Alan Pauls, tuvo entonces una distribución acotada y una recepción crítica aceptable. Después de ganar su autor la edición 2003 del importante premio Herralde con El pasado, la editorial Anagrama no sólo lanzó al mercado en lengua castellana la nueva novela sino que hizo lo propio con Wasabi, ampliando considerablemente su circuito original de distribución y lectura. ${ }^{2}$ Aunque conocido sobre todo por su trabajo crítico, Pauls ha gozado de un cierto prestigio como novelista debido al apoyo de figuras como Beatriz Sarlo o Ricardo Piglia y, particularmente, a la presentación que de él hiciera en un medio periodístico Roberto Bolaño al decir que era "uno de los mejores escritores latinoamericanos vivos”. En la actualidad, según el anuncio promocional característico del Premio Herralde, Pauls estaría en condiciones de convertirse en un "clásico del futuro". En ese marco hay que leer una novela que ha sido tan impulsada por un premio renombrado y por una intensa difusión, como escrita en un momento en el que, lejos de la consagración narrativa, su autor intentaba ser reconocido como novelista.

Wasabi cuenta la estada de un escritor argentino con Tellas, su mujer, en la ciudad costera de Saint-Nazaire, al norte de Francia, gracias a la invitación de la

2 Antes, Pauls había publicado otras dos novelas: El pudor del pornógrafo (1984) y El coloquio (1990). Como ensayista, se había destacado por su trabajo sobre Manuel Puig, La traición de Rita Hayworth (1986) y, después, lo haría con un ensayo sobre Jorge Luis Borges, El factor Borges (2000). Paralelamente a su actividad como narrador y crítico, Pauls se ha dedicado al periodismo cultural, escribiendo, entre otras, notas sobre literatura y cine para el suplemento Radar del diario Página/12. 
Maison des Écrivains et Traducteurs Étrangers (MEET) y de su editor Bouthemy para que se instale allí un par de meses y se dedique a escribir. Paralelamente a la comprobación de que le es imposible hacerlo en esas condiciones, el protagonista observa que un pequeño quiste que tenía en la base de su nuca comienza a alterar su textura y su tamaño hasta transformarse en una suerte de "espolón” al que intenta curar con una pomada homeopática que su mujer compara con el wasabi. Cansada de Saint-Nazaire, la pareja viaja a París donde se instala unos días, hasta que finalmente Tellas decide irse a visitar Londres. A partir de entonces el narrador sufre una serie de peripecias sin fin: se obsesiona con la idea de asesinar a Pierre Klossowski, por quien siente gran admiración; es golpeado por el portero de la casa donde vive el escritor; lo asaltan unos irlandeses que le roban todas sus pertenencias; vive como mendigo más de una semana en París; lo encuentra un colega chino que lo cuida hasta curarlo; se reencuentra con su mujer y se entera de que tendrá un hijo; vuelve en busca de Klossowski y alucina un atentado contra su vida; lo acosan unas prostitutas y una de ellas se acuesta gratis con él a cambio de gozar sentada sobre el "espolón”. Este es el final de la novela: en pleno goce de una prostituta que no le cobra y habiendo sublimado el acto parricida contra Klossowski, el escritor asume el sentimiento de paternidad y, presumiblemente, termina regresando a Buenos Aires, donde se supone que escribe la historia narrada en Wasabi en primera persona.

Wasabi no es simplemente una novela que cuenta la historia de un escritor al que le es imposible cumplir la deuda de escritura contraída con quienes lo premiaron y al que le sale una deformación en el cuello. Al narrar esta historia, Wasabi es también una respuesta ficcional a sus propias condiciones de producción. En 1992 Alan Pauls es efectivamente invitado a pasar un par de meses en la Maison des Écrivains Étrangers et des Traducteurs en la localidad francesa de Saint-Nazaire, donde hace años funciona un programa por el cual un grupo de escritores de diferentes partes del mundo es elegido para instalarse allí una temporada y escribir como resultado un texto de unas treinta páginas cuya única condición es mencionar la circunstancia que lo hizo posible. Se trata -como puede observarse- de un premio bastante especial porque está estrechamente emparentado con el encargo: es un premio que pone en deuda a quien lo recibe al obligarlo a contraer el compromiso de la escritura. Aunque en la elección esté contemplada la trayectoria de los ganadores, no es un premio dado a una obra ya escrita, sino a condición de una obra futura. Es una suerte de anticipo de capital simbólico, lo cual convierte a este premio en un instrumento de intercambio desigual. ${ }^{3}$

\footnotetext{
3 Para la definición de premio cultural como pieza objetivada de capital simbólico, a la vez que instrumento de intercambio y conversión con sus reglas y operadores particulares y con su propia trayectoria histórica en el campo cultural, sigo a English (109-135).
} 
De todos modos, ninguno de los otros escritores latinoamericanos que participaron del programa (como Reinaldo Arenas, Caio Fernando Abreu o Rodrigo Rey Rosa, para mencionar a los más conocidos) ni los otros argentinos premiados (entre ellos, Ricardo Piglia, César Aira y Sergio Chejfec) optaron por la salida de Pauls. Mientras en estos últimos casos, los escritores parecen querer pagar la deuda en la primera página y ponerse a escribir lo que de verdad les interesa, en el caso de Pauls la deuda sólo se paga con la escritura del libro entero.

En Wasabi, Pauls apela por igual a la alusión y al detalle para referir su estada en Saint-Nazaire, pero también hace de entrada una fuerte inscripción del yo en el relato: usa la primera persona y llama con el apellido de su propia mujer, Vivi Tellas, a la mujer del narrador; a la vez, en tensión con la figura de escritor que construye en el texto, aparece la figura del editor de la MEET, al que le pone el nombre de su verdadero editor en Francia: Bouthemy. Esta reelaboración de la situación de escritura de la propia novela viene a ser, en principio, casi una puesta en abismo de corte psicologista de la experiencia sufrida por el escritor ante el premio, el encargo y la deuda. Sólo que, atentando contra la lógica previsible de los hechos, el quiste en apariencia inofensivo que tiene en la base de la nuca le empieza a cambiar de textura y a crecer desmesuradamente. Allí donde debería descansar la cabeza del escritor -podría decirse- le crece un quiste incontrolable.

El quiste se convierte, así, en la primera marca en el cuerpo provocada por los conflictos vividos por el escritor con la escritura desde el momento en que se ha recibido una recompensa material anticipada. Al dar a través de esa recompensa material un adelanto simbólico al que hay que corresponder con la escritura futura, el premio termina causando un desajuste tal que provoca una deformación en el cuerpo. O dicho de otro modo: la imposibilidad de cumplir con la deuda, de salvar la descompensación simbólico-material, hace emerger la monstruosidad siempre latente del escritor. En ese punto, el origen de la deformidad termina resultando ambiguo: o pasa por la imposibilidad de cumplir con la deuda (es decir de estar a la altura de la doble recompensa) o pasa por aceptar un reconocimiento material allí donde debería haber sólo un valor simbólico (es decir ceder a exigencias extraartísticas). La diferencia no es menor y acarrea importantes consecuencias en la concepción de la escritura que presenta Wasabi. Porque la novela parece sostener, en un gesto barthesiano atribuible al propio Pauls, ${ }^{4}$ que sólo se puede escribir por deseo, por

\footnotetext{
4 La importancia de Roland Barthes en la formación de Alan Pauls ha sido mencionada por él mismo en algunas entrevistas y se observa en buena parte de su producción, en particular en aquellos textos que trabajan con lo autobiográfico o sobre los géneros de la intimidad. Entre los primeros, el gesto autobiográfico de Wasabi y El pasado culmina en el ensayo La vida descalzo. Entre los segundos, esa predilección se evidencia en la introducción y la selección de Cómo se escribe. El diario íntimo y culmina en el estudio preliminar a la edición en castellano de los primeros seminarios de Barthes en el Collège de France Cómo vivir juntos.
} 
placer y, mejor todavía, por goce. En ese marco, el compromiso, las presiones, el trabajo vienen a socavar la condición genuina de la escritura. Sin embargo -y en esta suerte de paradoja radica el conflico-, el narrador acepta (o precisa) las exigencias externas, es decir la deuda, aun cuando contradigan la concepción de escritura que sostiene en la novela.

En resumen: estamos ante un relato que, a través de lo que a primera vista puede verse como una paradoja, se entrega al conflicto que entabla la literatura con su valor económico. La retribución económica, que era un núcleo fuerte del reclamo profesional de los románticos y que potenciaba el derecho del artista sobre su obra, resulta ahora una cesión de ese derecho antes que una ratificación de la propiedad. Como si la autoría de la obra estuviera exenta de toda significación económica y se afincara en el terreno de la pura creatividad personal. Como si la única manera de liberarse del trauma material que atraviesa la narración fuera apelar a la imaginación ficcional para encontrar allí la respuesta liberadora.

Si en el Renacimiento una de las principales líneas de pensamiento explicaba la descendencia monstruosa como resultado de un desorden de la imaginación materna que impedía la natural reproducción de la imagen paterna, a partir de mediados del siglo XVIII el poder antes atribuido a la madre para crear una progenie singular pasó a ser asignado al padre. La relación entre la imaginación y el parecido, y entre los deseos incumplidos y el acto de generación, se modifica por completo cuando la literatura pone, en el lugar de la creación, al artista como padre monstruoso: "the Romantic metaphor of procreation -escribe Huet- restaged in its own terms the ideology of misguided desires that spawned aberrant offspring” (3). Con un sentido diferente al de épocas anteriores, el romanticismo hizo suya la idea de la obra de arte como creación y el papel del artista como procreador. El arte romántico se convirtió en una teoría de la generación y la imaginación dejó de ser la facultad de reproducir imágenes para convertirse en el poder de crearlas: “The vision of the Romantic artist as creator -explica Huet- borrowed a metaphor of creation from the theory that long ascribed the birth of monstrous progeny to the maternal imagination" (9). La monstruosidad representa la inquietud ante lo otro, y en la modernidad, lo otro viene a ser lo ajeno, las fuerzas externas que amenazan la especificidad de la escritura literaria: en esta tradición se inscribe Wasabi.

La escena final de la novela, en la que una prostituta se monta sobre el quiste del escritor sin cobrarle para gozar con la penetración del “espolón” -y a esto volveremos más adelante-, reelabora en clave ficcional el motivo de la prostitución en el arte, que tan eficazmente creó Baudelaire al oponer el arte al mercado y que marcó un punto de inflexión irrevocable en la tradición moderna. Con ese motivo, no sólo se redefinen los límites de la búsqueda creativa sino que se delinea la figura del artista moderno, cuya fuerte noción de propiedad literaria en términos de autoría 
y originalidad entra en dramática tensión con los progresivos condicionamientos de un mercado que el mismo romanticismo había impulsado a formar. Cuando las fuerzas del exterior ponen en crisis el acto de creación atribuido a los logros de la libertad individual, las nociones de autoría y de propiedad sobre la obra se tornan inestables. En este recorrido, como puede verse en Wasabi, el cuerpo puesto a la venta sirve también como moneda de pago.

La novela de Pauls no rompe con la idea de creación y de obra pero exhibe una dramática apertura hacia el exterior: premios, encargos, negocios con editores. Que en la figura de escritor de Wasabi encarne lo monstruoso viene a significar no tanto el repudio al contrato de escritura o el rechazo a la circulación mercantil de la obra, sino que el cuerpo del propio escritor no sale indemne de la relación con todo aquello que le resultaba ajeno. Viene a significar, en suma, que la imaginación ficcional sólo puede figurarlo como una deformidad.

Según el propio Pauls, Wasabi es "el fruto contrahecho de un acuerdo respetado en exceso". Según Beatriz Sarlo, se trata de "la novela de un vanguardista" que "le da una vuelta de tuerca a la transgresión a través del exceso de cumplimiento que la novela parece poner en escena”. En efecto, Wasabi presenta un exceso, pero ese exceso no sería tanto el resultado obsesivo del respeto al contrato, ni tampoco una transgresión vanguardista, sino más bien el mismo relato, que se plantea como la respuesta ofrecida a través de la ficción para elaborar sus condiciones materiales de producción. El exceso parece ser, antes que del orden de la forma (contrahecha o vanguardista), del orden de la imaginación. Porque el exceso no radica en el nivel de la escritura, sino en el acto de narrar ciertos contenidos. Así como en una instancia textual el exceso sería el modo de procesar el conflicto entre deuda y escritura que la trama resuelve por medio de su representación agudizada, en la instancia en que Wasabi supone una práctica cultural el exceso es la misma elección de escribir una novela sobre ese conflicto. El exceso, entonces, deja de ser deformidad o transgresión, para convertirse en la posibilidad de negociación entre los términos del conflicto. O mejor: es un modo imaginativo de negociar esa riesgosa inflexión de la ficción en mercancía.

En ese punto, entre la historia que narra Wasabi y la novela Wasabi habría, antes que un programa consecuente, una descompensación a partir de la cual plantear interrogantes sobre la viabilidad efectiva de los conjuros al mercado, sobre los límites de ciertas postulaciones de corte transgresor. Desde esta perspectiva, adherirse por completo al contrato no sería una vuelta de tuerca a la transgresión vanguardista, sino una sofisticada modalidad de negociación. 
COMPROMISO Y EXPERIENCIA

A lo largo de sus sucesivas peripecias, la novela presenta diversos motivos que, desde el siglo xix, han servido para ilustrar el conflicto del escritor con la dimensión económica del mundo: la relación entre literatura y cuerpo, el emblema del artista maudit, la analogía entre mercado y prostitución, por citar sólo algunas. En esos motivos en los que, de hecho, el protagonismo del quiste se hace evidente y va adquiriendo nuevos sentidos, se juega la relación con la inflexión mercantilista de la literatura. A la luz de estas consideraciones, es oportuno volver a la trama de Wasabi y revisar las salidas que propone, en el interior de la ficción, a las condiciones materiales de producción que escenifica, o sea el contrato y la deuda con la MEET.

Como telón de fondo de las peripecias hay dos conceptos que recorren toda la novela y a través de los cuales termina articulándose la ficción con la economía. Se trata de dos conceptos que han sido claves en la segunda mitad del siglo xx para comprender, respectivamente, la función del intelectual y la naturaleza de la narración: el compromiso y la experiencia. Por un lado, hay que entender la decisión de-según palabras del mismo Pauls- “trabajar con la experiencia” de esos dos meses de estada en Saint-Nazaire para resolver el conflicto ocasionado por el premio y ver cómo se imagina ficcionalmente esa experiencia. Por otro lado, hay que entender por qué se nombra como compromiso del escritor, en la novela, un contrato económico y cuáles son las consecuencias que arrastra ese desplazamiento. ¿O es, acaso, que el compromiso y la experiencia liberan a la escritura de su condición de mercancía sólo al costo de redefinirse en el interior de ese mismo marco de producción al que pretenden neutralizar o conjurar?

El momento en que se hace más explícita la relación del escritor con la MEET y su situación en Saint-Nazaire está a poco de avanzar en la novela: "No tenía compromisos literarios a la vista. El único que subsistía, y que yo violaba sistemáticamente todas las tardes, era el compromiso de escribir. Sentado ante el escritorio, se me había dado por amurallar la máquina con cuadernos y papeles, confiado en que esa presión material contribuiría a arrancarle las palabras que mi imaginación se resistía a dictarle. La única eficacia de ese asedio era desgraciadamente decorativa” (47). En la oposición entre un espacio-tiempo optimizado y la posibilidad de escribir, en la oposición entre mundo material e imaginación, Wasabi redefine la cuestión del compromiso en la literatura. Y en esa redefinición, la carga económica inherente a la acepción de obligación contraída borra todo rastro de compromiso político o social.

En el mercado de las letras, un escritor comprometido (como el protagonista de esta novela) es aquel que tiene una deuda con sus editores, aquel que tiene un 
contrato que cumplir. En los 90, el único compromiso posible parece establecerse con el mercado. El compromiso sartreano (y sus expresiones latinoamericanas de los años 60) ha quedado definitivamente atrás: el compromiso ya no se define por su naturaleza ideológico-política sino por su naturaleza ético-económica. La novela no habla de ese desplazamiento pero lo supone. De hecho, para hablar de la relación entablada con el editor a partir del premio recibido, utiliza una palabra que en otro tiempo tenía una carga claramente ideológica. Todavía hoy, referirse al compromiso en la literatura o a un escritor comprometido evoca un sentido completamente alejado de aquel que tiene en esta novela. Pero este sentido desplazado tiene una consecuencia aún mayor: al ser nombrado como compromiso, el contrato pierde parte de su carga económica y pone la deuda en términos éticos, a la vez que le agrega al propio compromiso un costado interesado que lo debilita ideológicamente. En suma: el concepto de compromiso como toma de conciencia aparece en la novela por omisión (y en esa omisión queda liquidado), mientras que el hecho de llamar al contrato "compromiso" termina legitimando su cumplimiento.

Para liberarse del compromiso (o sea: para alejarse de la presión material y acercarse a la fuente del relato futuro) el protagonista va en busca de lo que el propio Pauls llamó "el hueso puro de la experiencia”. En efecto, Wasabi levanta, frente a la literatura entendida como mercancía, el baluarte de la experiencia. El quiste, entonces, es el compromiso pero también es la experiencia. Es preciso subrayar la ambivalencia del quiste: ni el contrato económico que el narrador nombra como compromiso, ni las peripecias en Francia que reúne bajo la categoría de experiencia, son suficientes por sí solos para constituir un relato. Por eso, considero que-como adelanté- Wasabi resulta más de la negociación con lo que antes de la escritura de la novela parecía inconciliable, que de la resistencia.

Sin embargo, en el nivel más explícito de los hechos narrados, Wasabi parece postular que la experiencia es la gran condición del relato. Más todavía: casi a modo de recreación de las lecciones de Walter Benjamin, la novela plantea que para alcanzarese estado de experiencia es necesario, primero, haber sido despojado de todo (Benjamin, 1982 y 1973). Como si en el despojo y la pobreza (en la desterritorialización total) estuviera el umbral de la experiencia, las peripecias de la novela culminan cuando el escritor se convierte en homeless. Esta religazón entre la posibilidad de escribir y la noción de experiencia se practica, fundamentalmente, en la configuración de los dos espacios-tiempo que organizan la trama: Saint-Nazaire y París.

En primer lugar, Saint-Nazaire, lejos de ser el espacio-tiempo de la producción, como pretenden quienes entregan el premio, es presentado como el espacio-tiempo del consumo: el gabinete de trabajo se reemplaza por el shopping y el tiempo disponible para la imaginación novelesca se mide según los ritmos fugaces de la moda (¿sobrevivirán los fuseaux a la temporada en Saint-Nazaire?, se pregunta 
reiteradamente la mujer del escritor) o según los vacíos de la narcolepsia (que acosa al escritor durante su estadía en Saint-Nazaire). En ese espacio-tiempo confortable, entonces, el protagonista no se define por su naturaleza de escritor sino por su imposibilidad de serlo: pasea por las grandes tiendas, se prueba ropa, borra el tiempo del sueño como si fuera un tiempo suspendido en vez de perdido y termina posponiendo indefinidamente la escritura. Más todavía, la escritura aparece siempre, en Saint-Nazaire pero también en París, como un objeto: los papeles y cuadernos que rodean la máquina de escribir; los libros que contienen la traducción al francés de una novela del escritor que están empaquetados y esperan ser distribuidos en el mercado; el volumen que busca el protagonista en los estantes de una librería parisina.

En segundo lugar, París, en tanto espacio liberador frente a la presión del compromiso, tuerce todas las expectativas. París es, en ese sentido, el punto de inflexión de la novela: allí, con su mujer de viaje en Londres y obsesionado por la búsqueda de Klossowski para matarlo, el escritor es golpeado, robado, despojado; el escritor se convierte, finalmente, en mendigo. Según Josefina Ludmer, en Wasabi “se describe sarcásticamente, inclusive con el cuerpo en juego, la salida de un escritor argentino al exterior, a París, capital del siglo xix". ${ }^{5}$ Más aún: el escritor encara el viaje a París casi al modo del viaje estético decimonónico al centro de la cultura moderna. ${ }^{6}$ Sólo que, a fines del siglo xx, ni París es el espacio contemporáneo de la modernidad, como sí en la novela viene a serlo Londres con su heterogeneidad y con su flujo migratorio, ni en París el escritor latinoamericano es más el flâneur o el esteta, o siquiera el turista: ahora es un homeless. En París ya no hay deambular, ya no hay contemplación estetizante, ya no hay registro urbano: sólo vagabundeo y extrañamiento de sí mismo. Recién entonces, en ese viraje completo que lo deja totalmente fuera del mercado y de la circulación capitalista de los bienes, en ese estado de pérdida total que lo hace llegar al nudo de la experiencia ("el hueso puro de la experiencia”, lo llama Pauls), puede comenzar la primera etapa de su recuperación física y anímica, la etapa anterior a la cura del “espolón”.

Las experiencias vividas suponen, además, un nuevo conocimiento del tiempo. El tiempo de la experiencia (y el de la narración) no es más el tiempo disponible del ocio o el tiempo disponible y pago para consagrar a la escritura, ni es tampoco el tiempo de la moda o el de la narcolepsia: se trata de un nuevo sentido del tiempo que hace que una semana (lo que dura el estado de mendigo) pueda parecer una vida entera. El único riesgo es que esa experiencia se cosifique en el futuro, que -como anuncia la novela- se convierta en un museo donde los recuerdos conviven con los objetos disfuncionales que rodearon la vida del mendigo; entonces, los

\footnotetext{
5 Véase Ludmer, "Fin de siglo latinoamericano".

6 Sobre el viaje estético de los argentinos a París en el último cuarto del siglo xix y el modo en que su versión de Europa terminará identificada con el museo, véase Viñas (54-59).
} 
objetos se someten al coleccionismo y la experiencia se convierte para siempre en mera exhibición.

Ahora bien: la experiencia como mendigo, que parece otro recurso de resistencia a la mercantilización, no excede nunca los límites del individuo, no pone de manifiesto un modo de vida de corte colectivo o social, sino únicamente la degradación completa del cuerpo. El rechazo a la optimización del espacio-tiempo de la producción literaria por la vía de la experiencia sólo conduce al retraimiento o la introspección. La experiencia, en definitiva, se juega entera en el registro de lo individual. La salida al mercado (y, en el extremo, al capitalismo) no es en Wasabi, definitivamente, de orden político o social, sino una suerte de protección esteticista individual. Dehecho, tanto el concepto de compromiso como el de experiencia que se redefinen en la novela no dejan de reforzar, frente a los procesos de mercantilización, la individualidad. Y los avatares de la individualidad en el último cuarto del siglo xx, como bien lo demuestra Zygmunt Bauman en su Liquid Modernity, no han venido a negar los postulados del capitalismo y el mercado sino sólo a contribuir a la licuefacción de las relaciones clásicas entre sus elementos.

\section{TERAPÉUTICAS DEL ESCRITOR CONTEMPORÁNEO}

Sobre la base de esas relaciones de corte simbólico entre escritura por encargo, experiencia, deformidad del cuerpo y posibilidad del relato que propone la novela, la única cura que resulta eficaz para el escritor no es la operación por cirugía ni la dosificación homeopática de los médicos, sino los métodos integrales de la medicina oriental que, tras reconocerlo en las calles de París, le practica desinteresadamente un colega chino. Para curarlo, el dramaturgo chino-como casi siempre se lo denominale da, además de baños y de tés, algunos libros que pone al lado de la cama cada vez que sale para dejarlo a solas en el pequeño departamento. Aunque el escritor decida no leerlos, esos libros forman parte, también, de esa suerte de tratamiento integral. Al final del episodio, y siempre atenta a su propia hermenéutica, la novela dirá que esa cura es una “deuda impagable”. En todo caso, el único pago posible son las fotos del espolón que saca el dramaturgo para saciar ese interés que "iba de lo religioso a lo estético" (95).

En efecto, Wasabi es una novela de la cura. En ella, las afecciones del cuerpo son siempre sintomáticas y, para tratarlas, hay diversas, y en su mayoría ineficaces, curaciones. ${ }^{7} \mathrm{O}$, dicho de otro modo: mientras falla el diagnóstico, falla la cura.

\footnotetext{
7 La cuestión de las enfermedades y su cura se convirtió, paulatinamente, en una predilección de la narrativa de Pauls: en El pasado profundizaría el abordaje de la homeopatía, y ampliaría, casi en un sentido hipocondríaco, las enfermedades físicas y psíquicas (en particular del orden del lenguaje); en La vida descalzo también aparecería el problema de las afecciones de la piel. Lo monstruoso, de cualquier modo, no se propondría, en esos casos, en los términos de deformidad del cuerpo según sucede en Wasabi.
} 
La escena inicial, de hecho, es la de una cura improbable: el escritor acude a una médica de Saint-Nazaire para curarse el quiste y el fracaso homeopático es total. Sin embargo, a modo de compensación por la inutilidad específica de la pomada, se gana el efecto "wasabi": estimulante y lisérgico. La pomada "wasabi" -esa palabra que evoca lo otro, lo ajeno, lo exótico, y también lo picante, fugaz y ardiente propio del condimento japonés- juega la función de provocar el goce, no de o con la escritura, sino de los cuerpos. Aunque el wasabi parezca no tener ninguna relación con la cura, sí lo tiene si se considera que la novela -en ese punto en que el control crítico que ejerce sobre sí misma se le escapa- sostiene la idea de creación vinculada con la escritura literaria. La creación es imposible en Saint-Nazaire y el quiste sigue creciendo pese al wasabi; pero, gracias a él, aumenta cada vez el goce de los encuentros sexuales del escritor con su mujer y -lo sabremos promediando el relato- la procreación será posible. Así terminará la novela: cuando el escritor, imaginando a su mujer en el avión de regreso a Buenos Aires, sepa "que el hijo que velaba insomne a su madre dormida había encontrado por fin a su padre” (155).

La historia de la paternidad es la otra historia que, aparentemente, va en paralelo a la del compromiso y la deuda. Sin embargo, creo que ambas adquieren una dimensión que excede la mera historia de vida de un escritor en el que se reconocen ciertos rasgos del autor de la novela, si se las conecta entre sí por medio de la idea de monstruosidad resumida en el espolón. La historia de la paternidad del escritor también se inicia, a modo de complemento, con una supuesta enfermedad, con un falso diagnóstico y con una cura, pero todo en clave femenina. Si en Saint-Nazaire Tellas se aburre de la ciudad, en París comienza a sentirse descompuesta y a tener náuseas. Pese a que un médico le diagnostica ataque al hígado, ella le confiesa lo que considera la verdadera causa del malestar al escritor. No le dirá -no lo sabe todavía- que está esperando un hijo suyo, sino que "Era la torta gigantesca y barroca de París, su repostería amanerada y exhibicionista. Todo, decía, estaba en su lugar pero dos o tres veces, como si el repostero, temiendo que su destreza pasara inadvertida, la hubiese vuelto flagrante a fuerza de triplicar el énfasis decorativo del pastel” (61). Frente a las náuseas, las arcadas y la indigestión, Tellas declara: "Londres es mi cura” (62). Y tiene razón Tellas aunque el malestar se deba, más exactamente, a los primeros síntomas de su embarazo. Porque en Londres podrá darse cuenta de que lo que tiene no es un ataque al hígado pero tampoco una suerte de indigestión estética. Es Tellas, la mujer del escritor, la que consume (pastillas o vestidos) y la que se adecua a los ritmos de la modernidad (de la moda, de Londres), la que puede -en definitiva- crear (procrear).

El final de esta historia -como ya mencioné- es el final de la novela: después de dudas y paranoicas fantasías que le impiden reconocer al hijo en gestación, el escritor asume que será padre. Ahora bien, esta historia de la paternidad, es decir de 
la procreación, tiene su imprescindible correlato en la historia de un parricidio: la obsesión del escritor por matar a Pierre Klossowski. En Wasabi, Klossowski aparece como aquel que está cansado de la literatura y por eso se dedica ya sólo a pintar, mientras su obra es para el narrador excepcional: "la obra literaria de Klossowski, ¿no había tenido siempre para mí el brillo de una excepción, su carácter frágil, solitario y perecedero?” (27). No habría que ver en esta necesidad de terminar con su vida un crimen o un acto incomprensible dentro de la lógica general de la novela. Habría que tener en cuenta, en cambio, la relación planteada por el narrador entre la figura de escritor de Klossowski y su obra: "Si ser Klossowski era suficiente, ¿para qué hacía falta agregar una obra?” (28). Con la muerte deseada de Klossowski se termina, antes que con una obra, con un tipo de figura de escritor. Klossowski encarna, en ese sentido, al escritor maldito, al último libertino, al escritor del goce, al modernista total que lo deja todo. Acabar con él es borrar un cuerpo transgresor, moderno, que rechaza el mercado; pero un cuerpo, también, que cuando no encuentra ya su lugar sale de él para adoptar otra posición: el que dejó de escribir y se dedica a dibujar y pintar, el que deja de exponerse y se recluye en el interior. Un cuerpo que renuncia al afuera y que, antes que someterse a las inclemencias del exterior, prefiere cambiar de posición. Un cuerpo cuya única marca es el paso del tiempo. ¿Qué significa, si no un desfase de tiempo y espacio, declarar que estaba condenado "al trabajo forzado de cargar sobre sus hombros el peso de sus propias ruinas” (135)? Podría decirse que el modelo Klossowski es un modelo imposible o, con una formulación cercana a las teorizaciones de Huet: es imposible el parecido con aquel a quien se pone en el lugar del padre y en ello radica lo monstruoso (no hay parecidos con el padre: únicamente diferencias). Klossowski es, en tanto “excepción”, una excepción sólo posible en ciertas coordenadas de espacio y de tiempo.

El parricidio -y ahí sí la lógica novelesca de Wasabi resulta intacta- tiene dos finales. El primero es de corte realista: el escritor asiste a una de las raras apariciones públicas de Klossowski, donde su editor Bouthemy no lo reconoce pese a que él le grita su nombre en vano. El segundo es del orden de la imaginación: una antigua modelo de Klossowski, resentida por el maltrato infligido en largas sesiones de pose, atenta contra su vida y lo mata de una puñalada. La imaginación cumple claramente una función compensatoria: se exhibe como terapéutica y anticipa el modo en que la imaginación novelesca intentará dar cuenta de la situación enunciativa de Wasabi. La relación entre la historia del hijo y la historia del padre -en esa trama de parecidos y diferencias, de creaciones y procreaciones- produce la desestabilización de un típico gesto modernista: el narrador hubiera querido convertirse en parricida matando a Klossowski (el emblema del transgresor, quizás el último de los malditos) pero termina asumiendo su propia paternidad.

La relación que entablan ambas historias, sin embargo, no es directa. Entre la historia del parricidio y la asunción final de la paternidad tiene lugar la reescritura 
del motivo baudelairiano de la prostitución en el arte o del artista prostituido, que llega a Pauls, especialmente, junto con las reflexiones de Benjamin sobre la ciudad de París en el siglo xix. ${ }^{8}$ En esa última escena de la novela ya puede verse que las zonas de contacto entre el arte y el comercio se han modificado irreversiblemente y que las posiciones en el mercado son intercambiables. Paseando en medio de las prostitutas con su joroba, una de ellas lo resguarda de las burlas y, a cambio de gozar con el "espolón”, lo invita a tener relaciones sin pagar. Es en medio del clímax de ese acto gratuito que el escritor termina encontrándose consigo mismo, que logra vislumbrar el futuro y que asume la paternidad. Así, el espolón es primero un quiste que en el nivel simbólico puede leerse como deuda de escritura o como experiencia para la escritura; después, es casi una joroba que, en el nivel literal, se convierte en objeto de puro goce, ya sea estético (para el dramaturgo) o corporal (para la prostituta). La cura se completa en esa entrega a la prostitución del espolón, donde nuevamente ingresa lo compensatorio y donde el intercambio es liberado de la presencia del dinero. En el nivel de lo imaginario, se diría que cuando desaparece el quiste aparece el libro: la ficción ha dado una vuelta completa que va de las condiciones materiales que la hacen posible a la plena imaginación novelesca y de ésta a la escritura corporizada en libro.

En esas zonas de licuefacción de ciertos postulados modernistas que sostuvieron la trama hasta último momento, la historia narrada en Wasabi parece intentar salvar la descompensación que hay entre ella y las propias condiciones de posibilidad de la novela Wasabi. En esas zonas, podríamos encontrar un argumento incipiente que explique por qué las transgresiones modernistas han devenido tácticas de negociación. En ese sentido, con la caída del mito modernista del reconocimiento a largo plazo del escritor y con la apuesta por la consagración inmediata, que encuentra su vía más rápida en los premios, se hace difícil encontrar una poética de rechazo al mercado que se proyecte programáticamente en el interior de los textos. Más bien, como lo pone de manifiesto la lectura de la novela de Alan Pauls, el rechazo al mercado es algo que se puede narrar pero que difícilmente pueda convertirse en práctica cultural. De allí que el exceso que encierra escribir una novela sobre la imposibilidad de la escritura por encargo mientras se escribe una novela por encargo sólo dé por resultado una descompensación entre el nivel de la historia y el nivel de la novela.

\footnotetext{
8 Una aguda clarificación en términos estéticos y económicos de la relación entre la prostituta y el artista es la que hace Amanda Anderson al deslindar las tradiciones que en ella convergen: "But the nineteenth-century association between prostitution and art derived also from economic changes in the sphere of cultural production, and hence was never as romantic as the metaphor of self-creation suggests" (102-22).
} 
Desde el momento en que Wasabi se inscribe en el marco del compromiso entendido como escritura por encargo y deuda, no puede haber en ella una elección entre el rechazo al mercado y su aceptación: ésa es, como lo ilustra la ambivalencia del quiste, una falsa opción. El exceso no llega a ser una resolución sino una dramática denuncia. En ese sentido, el cuerpo deforme es el cuerpo que sufre y reacciona no porque rechaza la exposición, la exhibición y la circulación, sino, por el contrario, porque sí se expone, se exhibe y circula. ${ }^{9}$ Si ese cuerpo de escritor encarna lo monstruoso es porque se lo somete a ello. Habría que pensar que la reacción del cuerpo (su síntoma) no responde al rechazo del escritor a la mercantilización (convirtiéndolo en un transgresor) sino a que ese cuerpo no sale indemne de la exposición que el escritor le impone (participando de un premio, yendo a Saint-Nazaire o tratando estrechamente a su editor).

En ese marco, aceptar la paternidad y la procreación viene a seruna compensación interna frente a la deuda de la escritura imposible, que permite procesar el conflicto con la creación y la autoría literarias. La imaginación novelesca compensa la pérdida de autoría entendida en términos modernos y, devolviendo indirectamente la escritura al terreno de la creatividad, hace posible la creación de la novela. El escritor parece superar las presiones y liberarse de ellas para poder, de nuevo, escribir. El escritor ha aprendido a beneficiarse de su espolón para así liberarse, finalmente, de él. Volvamos rápidamente a una de las primeras menciones sobre la escritura, donde, imprevistamente, ya aparece la relación entre escritura y deformidad vinculada con el encargo. El narrador comenta las dificultades que le ofrece la máquina de escribir eléctrica con teclado francés:

lo peor era que ese duelo me consumía el tiempo y la fuerza que a duras penas había almacenado para escribir. Es cierto que cada tropiezo (el signo que aparecía siempre en lugar de la eñe, las “o” y las “i” fatalmente inacentuadas, las maliciosas trasposiciones de la tipografía) me ofrecía al mismo tiempo un inesperado gajo de literatura. Otro escritor, menos propenso que yo a escandalizarse por esos accidentes, habría celebrado y sabido explotar esos retoños de inspiración contrahecha. (48)

Podría concluirse que, al final, el escritor ha aprendido a explotar todos los retoños contrahechos a modo de inspiración; ha sabido aprovecharse de aquello que, de antemano, se pensaba monstruoso. Ha sabido jugar con la descompensación

\footnotetext{
9 Agradezco a Gabriel Giorgi por sugerirme que avanzara en esta línea de lectura al escuchar una primera versión de este trabajo cuando la presenté en el Departamento de Lenguas Romances de la University of Southern California, en febrero de 2004; en efecto, la exhibición y circulación del cuerpo de los escritores contemporáneos está en sintonía con la exhibición y circulación de su producción literaria.
} 
provocada en su propia figura por las reglas del juego de la circulación en el mercado.

No querría leer esta descompensación, tentada por un facilismo explicativo que considero anacrónico, como el resultado de un gesto cínico o de desilusión posmoderna (no hay vanguardismo sino cinismo, no hay transgresión sino desilusión). Si la conversión de la literatura en mercancía viene a resultar inevitable, los premios parecen presentarse, al menos frente a otros instrumentos que propician el intercambio entre el capital cultural y el capital económico, como instrumentos relativamente flexibles de negociación. Es cierto, como señala English, que los premios les ofrecen a aquellos escritores y artistas "serios" que saben jugar con ellos en beneficio propio la posibilidad de una eficacia subversiva por la vía de una "apropiación inadecuada" (su caso testigo es el de Toni Morrison, y considero que para la Argentina Plata quemada de Ricardo Piglia, la controvertida ganadora del Premio Planeta, resulta un excelente ejemplo). ${ }^{10}$ En ese punto, habría que pensar en la novela El pasado con la que Pauls ganaría casi una década después el premio Herralde y cómo gracias a ese premio consiguió no sólo una circulación transnacional de sus libros sino también de su imagen; y lo logró a tal punto, que la novela fue llevada al cine en coproducción internacional y tuvo una distribución del mismo tenor. Estamos lejos de una "apropiación inadecuada" extrema, pero ello no obsta a que ciertos aspectos de El pasado (su extensión, para empezar) se encuadren en el tipo de apropiación explicada por English. En todo caso, Wasabi no representó, en la trayectoria intelectual de Pauls, un corte con la situación de enunciación que la novela pone en escena, sino su procesamiento ficcional a través de la forma monstruosa del quiste.

Por todo ello, la lectura de Wasabi me incita a pensar en otra posibilidad para resolver esa falsa dicotomía entre poética de la transgresión y lógica del mercado, una posibilidad que no remite ya a una consideración sociológica de las tácticas del escritor sino a los dominios de la imaginación. Porque, en su descompensación, Wasabi le ofrece a la ficción la oportunidad de convertirse en la compensación simbólica de la recompensa material que la hace posible. En su gesto antimodernista, el escritor no puede hacer más que aceptar el compromiso de la MEET; en su gesto modernista, no puede hacer más que ficcionalizar la experiencia del rechazo. En ese vaivén, el escritor de Wasabi se encuentra con su fantasma, con ese escritor (el vanguardista, el transgresor, el maldito, el homeless) para el cual ya no hay ni tiempo ni espacio posibles. Ese escritor en cuyo propio cuerpo ya no puede reconocerse.

\footnotetext{
${ }^{10}$ Para una lectura de la lógica de los premios literarios en términos de práctica cultural que involucra
} al mercado pero también a los escritores que participan de ellos, véase Laera. 
BiBLIOGRAFÍA

Aira, César. Nouvelles impressions du Petit Maroc. Saint-Nazaire: MEET, 1991.

Anderson, Amanda. "Prostitution's Artful Guise". Diacritics XXI/2/3 (veranootoño 1991): 102-122.

Bauman, Zygmunt. Modernidad líquida. Buenos Aires: FCE, 2003.

Benjamin, Walter. "Experiencia y pobreza”. Iluminaciones 1. Madrid: Taurus, 1982.

“El narrador”. Discursos interrumpidos I. Madrid: Taurus, 1973.

Bolaño, Roberto. "Ese extraño señor Alan Pauls" <http://www.reforma.com>; extraído del suplemento El Ángel del diario mexicano Reforma (3 de noviembre de 2002).

Chejfec, Sergio. Cinco. Buenos Aires: Simurg, 1998.

English, James F. "Winning the Cultural Game: Prizes, Awards, and the Rules of Art”. New Literary History 33 (2000): 109-135.

Huet, Marie-Hélène. Monstrous Imagination. Cambridge: Harvard UP, 1993.

Laera, Alejandra. "Los premios literarios: recompensas y espectáculo". El valor de la cultura. Cultura y mercado en el capitalismo latinoamericano. Á. Fernández Bravo, L. Cárcamo-Huechante y A. Laera, eds. Rosario: Beatriz Viterbo, 2008.

Ludmer, Josefina. "Fin de siglo latinoamericano" (entrevista de Marcos Mayer). Primer Plano, Página/12 (8 de enero de 1995).

Pauls, Alan. Wasabi. Buenos Aires: Anagrama, 2005.

La vida descalzo. Buenos Aires: Sudamericana, 2006. Cómo vivir juntos. Buenos Aires: Siglo XXI, 2003.

Cómo se escribe. El diario íntimo. Buenos Aires: El Ateneo, 1996.

El pudor del pornógrafo. Buenos Aires: Sudamericana, 1984.

El coloquio. Buenos Aires: Emecé, 1990.

Manuel Puig. La traición de Rita Hayworth. Buenos Aires: Hachette, 1986

El factor Borges. Nueve ensayos ilustrados. Buenos Aires: FCE, 2000.

Piglia, Ricardo. Une rencontre en Saint-Nazaire. Saint-Nazaire: MEET-Arcane 17, 1989.

Sarlo, Beatriz, junto a Héctor Tizón, Juan Carlos Martín y Alan Pauls. “Experiencia y lenguaje I”. Punto de Vista XVIII/51 (Buenos Aires, abril de 1995).

Viñas, David. Literatura argentina y realidad política [1964]. Buenos Aires: Centro Editor de América Latina, 1982. 